\title{
Policy Options to Combat the Digital Divide in Western Europe
}

\author{
Rod Carveth \\ Texas Tech University, \\ Lubbock, TX, USA
}

docrod99@hotmail.com

\author{
Susan B. Kretchmer \\ The Johns Hopkins University, \\ Baltimore, MD, USA
}

susankretchmer@yahoo.com

\begin{abstract}
This paper reviews the digital divide in Western Europe, as well as policy options for combating that divide. While age, income and gender are significant predictors of the digital divide in Western Europe, geography plays a crucial role. The countries in Southern Europe have less computer and Internet penetration than their Northern European counterparts. The paper then discusses four policy options for combating the divide, suggesting that the most effective solution would be private/public partnerships.
\end{abstract}

Keywords: digital divide, diffusion, Internet, policy

\section{Introduction}

There is no question that the "digital divide" - the unequal access to computers and the Internet caused by such social and economic factors as gender, income, race, and geography - poses long-term problems for a number of nations across the world. The ability to use and apply digital information is one of the key skills for future economic mobility, particularly in developing nations. Economic and social progress may not be as real or as sustainable when large numbers of people are excluded from receiving its benefits. So important has the digital divide become worldwide that the major advanced industrial countries (known as the "G8" countries) have formed a "dot force" to develop solutions for these technological disparities (BBC Online, 2000).

When looking at the problem from a global perspective, the digital divide takes two forms. The first form consists of the national digital divides within a country of the world. Considerable policy-making and resource allocation have taken place in such countries as the United States, Canada, and Australia to find ways to ensure that citizens have access to the Internet.

The second form of the digital divide is the international schism between the "information-rich" and the "information-poor" countries. The international digital divide is

Material published as part of this journal, either on-line or in print, is copyrighted by the publisher of Informing Science. Permission to make digital or paper copy of part or all of these works for personal or classroom use is granted without fee provided that the copies are not made or distributed for profit or commercial advantage AND that copies 1) bear this notice in full and 2) give the full citation on the first page. It is permissible to abstract these works so long as credit is given. To copy in all other cases or to republish or to post on a server or to redistribute to lists requires specific permission and payment of a fee. Contact Editor@inform.nu to request redistribution permission. based largely on the vast economic disparities between the wealthier, industrialized nations and the poorer, developing nations. For example, high-income countries with $16 \%$ of the world's population have $90 \%$ of the world's Internet hosts. The United States has more computers than the rest of the world combined (BBC Online, 2000).

In this paper, we first apply diffusion theory to the understanding of how patterns of technology adoption tend to be unevenly spread, and what factors affect that process. Secondly, we examine the digital divide as it currently exists in Western Europe - the region of the world that is only behind North America in terms of being "wired." Third, from the experience of attempts to correct the digital divide in the United States, we discuss four possible policy options that Western Europe could pursue to correct their digital divide. Finally, we project the likely option Western Europe might adopt.

\section{Diffusion Theory}

One way of explaining the international digital divide is by applying diffusion theory. According to diffusion theory, adoption of technological innovations is a function of one's innovativeness, or willingness to try new products (Rogers, 1995). The theory proposes that a small segment of the population (usually less than 3\%) accepts the risk of adopting a new idea, product, invention, or behavior before anyone else. Eventually, if others see the benefits they can obtain from adopting the innovative activity, then they will adopt the new idea or product (Markus, 1987, Ryan \& Gross, 1943; Rogers 1983; Valente, 1993). The nature of diffusion and adoption of a new communication technology, such as the Internet, can be viewed from the perspective of diffusion theory.

The theory suggests there are four main elements in the diffusion process: 1) the innovation, 2) communication 


\begin{tabular}{|l|r|r|r|}
\hline & Per GDP & Phone per 100 & \multicolumn{2}{|l|}{$\begin{array}{l}\text { Computers } \\
\text { per 100 people r }\end{array}$} \\
\hline Africa & 823 & 2.45 & .88 \\
\hline Asia & 2,144 & 8.32 & 2.52 \\
\hline Americas & 14,178 & 33.13 & 21.34 \\
\hline Europe & 12,109 & 38.48 & 14.63 \\
\hline
\end{tabular}

Source: ITU, 2000.

\section{Table 1 - Technology across the Continents}

channels, 3) time, and 4) the social system. Rogers (1995) has characterized the diffusion process using a bell-shaped curve to illustrate how long it takes to adopt an innovation in a population. He classified the adopters of innovations into five categories based on how long a period of time they take to adopt an innovation: innovators, early adopters, the early majority, the late majority, and laggards. Factors such as risk willingness, wealth, cosmopoliteness, education, and social pressure influence individuals' adoption of an innovation.

Rogers $(1995,1983)$ proposes that the concept of "critical mass" is crucial to the diffusion process. Critical mass refers to the point at which the number of adopters is large enough for the growth process to become self-sustaining. An innovation is of little value unless other individuals also adopt it (Valente, 1995). For example, if people feel the cost of subscribing to an Internet service outweighs the benefits, then there will be too few subscribers for this innovation to become self-sustaining. Thus, critical mass is an important consideration in understanding the conditions under which reciprocal behavior gets started and becomes self-sustaining (Markus, 1987). For any medium to be considered a mass medium and, therefore, economically viable to advertisers, a critical mass of adopters must be achieved (Morris \& Ogan, 1996). Interactive media, such as the Internet, only become useful as more and more people adopt them. As Rogers (1986) noted, the usefulness of a new communication system increases for all adopters with each additional adopter. At the present time, the Internet has reached the critical mass threshold suggested by Rogers (1995) to assure that its adoption rate will become self-sustaining.

Internationally, a nation's adoption and extent of use of the Internet varies due to numerous factors, chief among them socioeconomic factors such as income (Rogers, 1995).

Per capita Gross Domestic Product (GDP) generally predicts the likelihood of the adoption of the Internet. Per capita GDP is generally related to the number of telephone lines per 100 people in a region. The number of phone lines is a leading indicator for the level of universal ser- vice in telecommunications. Of the world's nearly 850 million phone lines, $64.5 \%$ are located in only 30 industrialized nations. On the other hand, the nations with the lowest per capita Gross Domestic Product (GDP) have only 1.6 telephone lines per 100 people (OECD, 2001). Per capita GDP is also related to the number of computers per 100 people in a country, another prerequisite to obtaining Internet service. Table 1 demonstrates some of the global disparities that exist across these two indicators.

Table 1 shows that the higher per capita GDPs of the Americas and Europe result in greater numbers of phone lines and computers. The relationship between per capita GDP and phone lines/computers per 100 people is even more striking when comparing the most industrialized and least developed nations in those regions (Table 2).

Table 2 clearly shows that the number of phone lines and computers is proportional to a nation's per capita GDP.

Other factors may also account for a country's adoption pattern. Valente (1995) has observed that social networks are a major influence affecting the adoption of a new idea, product, or technology over time. A social network is the pattern of friendship, advice, communication, or support that exists among the members of a social system (Burt \& Minor, 1983).

Another factor that crucially affects the nation's Internet diffusion is infrastructure. In terms of the Internet, existing telecommunication facilities are critical to understanding variations in the spread of the Internet (Hargittai, 1999). A country's infrastructure, as well as the capacity of its international links, plays an important role in the diffusion process (Bazar \& Boalch, 1997).

In examining the effect of the above factors, Kwon (2001) found in a study of 82 nations that countries with higher per capita income, more education, higher network connectivity, sufficient technological infrastructure, and more competitive market environments were more likely to adopt the Internet earlier than other nations and to use the 
Internet more often to get information. The economic stability of a nation, language barriers, and government policies were less predictive of the adoption of the Internet as a new communication medium.

\section{Comparing the United States and Western Europe}

By far, the United States and Western Europe lead the world in Internet penetration. This is not surprising as both regions contain advanced industrialized economies. Still, while the United States is rapidly approaching a 60\% Internet penetration rate, Western Europe has just recently broken through the $30 \%$ barrier (a figure at which a communication medium becomes a "mass" medium). But a closer examination of Internet usage in specific Western European countries shows that those with a lower level of industrialization bring down the average for the entire region. For example, the high Internet penetration rates of Sweden and Iceland (64.68\% and $69.80 \%$, respectively) are in effect canceled out by the Internet penetration rates of the less industrialized Greece and Turkey $(13.15 \%$ and $3.71 \%$, respectively).

A 2000 study comparing Internet use in the United States and Europe revealed that while $26 \%$ of Americans in the lowest socio-economic class went online, only $7 \%$ in the corresponding Western European class did (NUA, 2000). The same study found that $44 \%$ of Americans in the 55 to 64 age bracket used the Internet, compared to only $12 \%$ of Western Europeans in the same age group (NUA, 2000). The same study found that $55 \%$ of American men and $52 \%$ of American women used the Internet. By comparison, only $34 \%$ of Western European men and $20 \%$ of Western European women used the Internet (NUA, 2000).

A close examination of the digital divide in Western Europe reveals that the region is split almost evenly between the "wired" Northern countries and the "unwired" Southern ones (Wakefield, 2002). One reason for this geographic divide might be attributed to the income gap between the two areas. For example, the per capita GDP for Denmark is $\$ 26,000$ compared to $\$ 16,700$ in Spain (ITU, 2000). Per capita GDP alone may not explain this, however, as the tax rate in Denmark (45\%) is more than twice as high as that of Spain (20\%), which reduces the disposable income gap.

The North/South divide results from a number of economic, political, and cultural differences. The liberalized telecommunication policies in many Northern European nations are one factor. With telecommunication liberalization comes a drop in phone charges, thus making it much more affordable for a user in Scandinavia to access the

\begin{tabular}{|l|l|l|l|}
\hline & $\begin{array}{l}\text { Per capita } \\
\text { GDP (\$) }\end{array}$ & $\begin{array}{l}\text { Phone lines } \\
\text { per 100 people }\end{array}$ & $\begin{array}{l}\text { Computers } \\
\text { per 100 people }\end{array}$ \\
\hline Africa & 3,107 & 13.77 & 6.01 \\
\hline South Africa & 664 & 0.66 & 0.27 \\
\hline Cameroon & & & 28.69 \\
\hline Asia & 30,105 & 55.75 & 1.64 \\
\hline Japan & 898 & 3.88 & \\
\hline Philippines & & & 51.05 \\
\hline Americas & 32,198 & 66.40 & 2.01 \\
\hline United States & 1,984 & 7.61 & 29.69 \\
\hline El Salvador & & & 0.8 \\
\hline Europe & 26,214 & 58.79 & \\
\hline Germany & 430 & 12.68 & \\
\hline Moldova & & & \\
\hline
\end{tabular}

Source: ITU, 2000

Table 2 - Most wired and least wired countries in selected continents 


\begin{tabular}{|c|c|c|}
\hline & Internet Users & Internet Penetration Rate \\
\hline Turkey & $2,500,000$ & $3.71 \%$ \\
\hline Greece & $1,400,000$ & $13.15 \%$ \\
\hline Portugal & $3,600,000$ & $34.37 \%$ \\
\hline Spain & $7,890,000$ & $19.69 \%$ \\
\hline Italy & $19,250,000$ & $33.37 \%$ \\
\hline France & $16,970,000$ & $28.39 \%$ \\
\hline Austria & $3,550,000$ & $43.45 \%$ \\
\hline Switzerland & $3,410,000$ & $46.82 \%$ \\
\hline Germany & $30,200,000$ & $36.37 \%$ \\
\hline Belgium & $3,400,000$ & $33.14 \%$ \\
\hline Netherlands & $9,280,000$ & $58.07 \%$ \\
\hline Ireland & $1,300,000$ & $33.67 \%$ \\
\hline U.K. & $34,000,000$ & $56.88 \%$ \\
\hline Denmark & $3,230,000$ & $60.38 \%$ \\
\hline Norway & $2,460,000$ & $54.40 \%$ \\
\hline Sweden & $5,740,000$ & $64.68 \%$ \\
\hline Finland & $2,690,000$ & $51.89 \%$ \\
\hline Iceland & 195,000 & $69.80 \%$ \\
\hline
\end{tabular}

Sources: NUA 2001, BBC Online 2001

Table 3 - Number of Internet Users and Internet Penetration Rate for Countries in Western Europe

Internet than one in France who pays on a per-minute basis. The English-dominated nature of the Internet is another factor. Though only $28 \%$ of all Western Europeans speak some level of English, 78\% of the population of the Netherlands speaks English as a second language.

Table 3 illustrates Western Europe's geographical digital divide.

\section{Internal Factors Contributing to the Digital Divide in Western Europe}

In addition to the North/South regional divide, most Western European nations have similar internal factors that predict their national digital divides. As with the United States, these "intra-national" digital divides come about from two major factors: age and income. Unlike the United States, however, gender is also a major contributing factor to the intra-national digital divides. 


\section{Age}

In many countries in Western Europe, older demographic groups are less likely to use the Internet than younger demographic groups. For example, in the United Kingdom, $85 \%$ of those aged 16-24 has Internet access compared to just $15 \%$ aged $65-74$ and $6 \%$ over the age of 75 . This finding is paralleled in Spain, where only $1 \%$ of Internet users are over 60 ; Sweden, where only $8 \%$ of those online are 65-74; and Denmark, where only $14 \%$ of those over 70 have ever been online. By contrast, twothirds of Dutch Internet users are under the age of 35. As with the United States, older citizens are being excluded from the benefits of this new communication medium (NUA, 2001). So-called "silver surfers" also differ in the reasons for their Internet use. In the United Kingdom, men over the age of 55 use the Internet to pursue hobbies and seek out information, while senior women use the Internet to communicate with family and friends (BBC News Online, 2002, August 21).

\section{Income}

In the United States, the higher the household income, the more likely that the members of that household will own a computer and use the Internet. The same pattern is true throughout Western Europe. In the United Kingdom, only $23 \%$ of the lowest income group is riding on the information superhighway, while $68 \%$ of those in the highest income group are passengers. In France, $74 \%$ of the highest income bracket has a personal computer, compared to $11 \%$ in the lowest income bracket. Only $30 \%$ of the unemployed in Ireland are "familiar" with computers, as opposed to $84 \%$ of students and $64 \%$ of those in the workforce. The situation is even worse in Italy, where only $9 \%$ of the unemployed in Italy have ever gone online, compared to $70 \%$ of students and $38 \%$ of the workforce. Thus, the groups that could most benefit from having access to the information economy are the least likely to be using its tools (Meland, 2000; NUA, 2001).

\section{Gender}

In the United States, men and women make up roughly the same number of Internet users. In contrast, consider the following: only $40.5 \%$ of French Internet users are female; there are 2.6 Italian men online for every one Italian woman online; only $33.5 \%$ of the Spanish online population is female; and only $36 \%$ of the German online population is female. In Western Europe, using the Internet is an activity that men are more likely to do than women. Given that Western European women have fewer highincome jobs and have lower annual incomes, this "genderized" digital divide puts women at an increased economic disadvantage (Meland, 2000; NUA, 2001).

\section{Geography}

As in the United States, where Internet penetration is higher in the northeastern and western states than in the southern states, there are regional differences within Western European countries as well. For example, $56 \%$ of people living in the southern and eastern regions of the United Kingdom (a region which includes London) regularly use the Internet compared to a $23 \%$ usage rate in Wales (MediaGuardian, 2002, March 11).

\section{Race/Ethnicity}

Race/ethnicity is a major predictor of information "haves" and "have-nots" in the United States. In Western Europe, race does not appear to be a major cause of the digital divide, although the effect of race in predicting the Western European digital divide might be masked by income.

In summary, two digital divides plague Western Europe. First, there is a regional digital divide between Northern European countries and Southern European ones. Secondly, Western European countries face their internal digital divides based on age, income, and gender. The next section reviews four different options for solving both the regional and the intra-national digital divides in Western Europe.

\section{Solutions}

The United States has been suffering from a persistent digital divide for most of the last decade (U.S. Department of Commerce, 2000). Many solutions have been offered as to how to deal with the inequity in Americans' technology acquisition. These proposed solutions fall into four categories - the marketplace, government action, philanthropy/community action, and public/private partnerships. Those concerned about the digital divide in Western Europe might be well advised to look more closely at these U.S.-based categories of solutions.

\section{The Marketplace}

This solution to the digital divide suggests that the market will fix the problem by allowing the basic laws of supply and demand to be the primary engines for change. The government's role should be restricted to nurturing competition and funding basic research.

This approach cautions that policymakers should be patient and let the market fulfill consumers' evolving needs instead of rushing to create expensive and unwarranted new federal programs. Historically, new technologies spread slowly. First the wealthy get the technology, then the middle classes and the poor, but eventually everyone gets the technology. In addition, it appears that the newer the technology, the quicker it spreads. For example, it 
took 46 years for $25 \%$ of the American population to get electricity while it took 35 years for $25 \%$ of the population to get telephone service. By contrast, it took just 16 years for $25 \%$ of American households to get a personal computer and only seven years for $25 \%$ to get Internet access. The free market proponents thereby claim that the digital divide is not a question of "haves" and "have-nots," but of "have-nows" and "have-laters."

As evidence of the marketplace at work, the price of personal computers has declined to the level of a television set. A basic unit that will allow the user to access the Internet, do word processing, or create a Web page can be purchased for between $\$ 300-400$. In addition, market forces of supply and demand have made Internet access readily available and affordable to most users. For example, from October 1999 to September 2000, the average cost of Internet access for 20 hours per month at peak times fell by $24 \%$, and $21 \%$ at off-peak times; for 40 hours of peak usage it fell $27 \%$, and $26 \%$ at off-peak. As the Internet technology marketplace matures, prices will fall even more, making Internet access affordable to all that want it.

\section{Governmental Action}

Opposing the pro-marketplace voices are those who believe that the digital divide is a serious enough problem to warrant governmental involvement. Proponents of governmental intervention argue that it was not the marketplace that built the interstate highway system, alleviated the country's civil rights problems, or implemented the space program. Rather, it was the government who assumed these massive responsibilities. It appears that many Americans agree - a recent poll revealed that $57 \%$ of the respondents agreed with the notion that the government should "help low-income get access to computers and the Internet" (NPR, 2000).

The pro-marketplace faction argues that the eventual spread of Internet access in the next few years will parallel the gradual spread of access to television since 1948. Yet, critics note that this is an unfair comparison. Television "is basically a passive form of entertainment ... [t] he new media [the Internet] require the active, informed, literate participation of a user" (Tapscott, 1997). Thus, the spread of television access will not be replicated by the Internet, which takes deliberate effort by literate and motivated users, as opposed to the inherently passive nature of television. Consequently, society cannot rely on the market to bridge the digital divide, but, rather, the government must act.

Those who take this position advocate one of two options for action by the government. First, because the digital divide is a serious social and economic problem, the gov- ernment - at the federal, state and local levels - should attack the problem through direct funding. The second solution is to combat the divide through governmental legal, regulatory, and tax policies. We review an example of each solution below.

\section{Federally Funded Programs}

The U.S. Department of Education has allocated over $\$ 135$ million in grants to train 400,000 teachers to use information technologies more effectively in the classroom and the 'Kids 2000' program. Kids 2000 will provide each of the 2,300 Boys and Girls Clubs in America an average of 10 computers. In addition, Kids 2000 will provide every Boys and Girls Club with Internet access and instructors to show the youths how to utilize the technology.

\section{Federal Regulations and Tax Policy}

A prime example of using regulatory and tax policy to combat the digital divide is the implementation of the Schools and Libraries Universal Service Fund. Known as the "e-rate," the program allows primary and secondary schools and libraries to receive basic and advanced telecommunications services at discounts from $20-90 \%$ below commercially available rates. The most disadvantaged schools and libraries (based on the percentage of students eligible for the national school lunch program), as well as those in rural areas, receive the highest discounts. Financed with revenues from long-distance telephone charges, the e-rate provides approximately $\$ 2.25$ billion in funds to schools and libraries.

State and Local Government Action. Even some advocates of governmental action believe that the federal government is too unwieldy, distracted, meddlesome, and/or inept to deal with the digital divide properly. Instead, they believe that government action on the digital divide must come from the state and local levels.

An exemplar of state governmental action is Maine's effort to provide every seventh-grader with a free laptop computer that the student would keep after graduation (Rosen, 2000 ). With $\$ 50$ million in state funds, along with $\$ 15$ million from federal and private sources, Maine is providing each student with a laptop on the first day of the seventh grade. The computers remain school property until graduation, though students can take them home for homework and research. Further, the state pays the cost of equipping half of all the K-12 teachers in the state (the local school districts paying for the other half). As many as 21,000 students and teachers would receive a free laptop in the first year of the program.

Municipal governments are getting involved. Boston is Municipal governments are getting involved. Boston is the perhaps the best example of local government action against the digital divide (Page, 2000). The city's Digital 
Bridge Boston initiative features two programs: TechBoston and Technology Goes Home. TechBoston is the citywide technology training program for public school students. In return for their training, students of TechBoston provide teachers, schools, and the Boston Public Library with technology support. The Technology Goes Home program provides low-income families with a free computer, Internet access, and training.

An example of the positive effects of these efforts is a project conducted in Camfield Estates, a 102-unit, lowincome housing development in Roxbury, Massachusetts. A computer and a high-speed Internet connection were provided to each unit and residents were provided with training in the use of computer hardware and software. Evaluation of the program revealed that the use of the technology introduced into Camfield Estates increased the size and range of residents' social networks. Residents experienced increased empowerment and improved access to jobs and other resources outside of the local job market (Hampton, O'Bryant and Pinkett, 2002, August).

\section{Philanthropic and Community Efforts}

Outside of government action and free market solutions, many believe that the digital divide can be bridged through community efforts and philanthropy. Supporters of this option hope that corporations, civic organizations, foundations, and wealthy individuals will realize the importance of the digital divide. The proposition is that if America's philanthropic spirit can be harnessed, the digital divide could be bridged.

The most high-profile example of individual giving is $\mathrm{Mi}$ crosoft Chairman Bill Gates, who donated $\$ 1$ billion to fund minority scholarships in technology fields through the Gates Foundation.

On the corporate level, 3Com Corporation donated \$1 million in networking equipment and consulting services to ten U.S. cities to implement programs to help minorities and low-income families access the Internet ("3Com," 2000). For example, in Glasgow, Kentucky, 3Com implemented a citywide network to link all residents to the public schools and city services. 3Com also installed computer kiosks throughout the city of New Orleans to connect at-risk youth with training alternatives and job opportunities.

Non-profit foundations are also very active in closing the digital divide. For example, the Verizon Foundation's work includes establishing an online resource center to assist schools and libraries to apply for the Federal "erate" program and offering $\$ 500,000$ in workforce development grants to communities in Illinois and Indiana.
Because the digital divide is linked to a number of society's challenges (illiteracy, grossly uneven distribution of wealth, etc.), many community action organizations are working in some part to close the digital divide. For example, the Charles River Public Internet Center of Waltham, Massachusetts works to ensure that every member of the community has equal opportunity to become computer literate and has access to the Internet and office software. In addition, the Austin Free-Net provides free, public Internet access to all residents of Austin, Texas.

With the current economic recession in the United States, however, the level of giving from these organizations and individuals may not be enough to overcome the barriers posed by the digital divide.

\section{Private/Public Partnerships}

The 2000 election brought about a shift in the federal government's priorities and attitudes towards the digital divide. The most immediate manifestation of this shift was the threat of limiting or cutting the amount of government money being devoted to digital divide issues. Therefore, there are some who feel that the most practical solution is to form private/public partnerships to share the burden of running digital divide programs. Of the scores of partnerships battling the digital divide, two stand out:

1) "Plugged In" of East Palo Alto, California offers free Internet access and computer training to the residents of one of the poorest and most ethnically diverse areas of California. Plugged In trains students in Internet and computer basics, as well as providing them with a 10week training program covering graphic design and website development. Volunteers from such companies as Intel, Sun Microsystems and Cisco Systems teach these training sessions. As a result, Plugged In offers its students world-class, hands-on training in some of the most marketable information technology skills.

2) "PowerUP" is an organization that is a combination of not-for-profit organizations, for-profit businesses, and government agencies. Founded by Steve Case, chief executive officer of the world's largest Internet service provider, America Online, PowerUP's main mission is to fulfill "Five Promises": an ongoing relationship with a caring adult; safe places and structured activities; a healthy start; marketable skills through effective education; and an opportunity to give back through community service (PowerUP, 2002). Backed by AOL Time Warner, Cisco Systems, Hewlett-Packard, and the Waitt Family Foundation, PowerUP has established 500 centers across the country, including such underserved areas as Appalachia and rural Mississippi. 


\section{Conclusion}

\section{What's Best for Western Europe?}

If this had been the mid-1980s, there is little question that Western Europe would have tackled the digital divide with massive government programs. With the trend to the privatization of communication systems in the last 15 years, it is impossible to put the marketplace philosophy genie back in the bottle. In addition, given the rapidity with which some European countries change governments (e.g., Italy), a strictly governmental action orientation to solving the digital divide would be problematic. Even the European Commission (EC) recognizes the important role of the marketplace. A November 2001 EC report called for combined efforts by "public and private actors at all levels" (Commission of the European Communities, 2001, p. 35). In December 2001, the Commission adopted a new regulatory framework regarding information technologies that provides Europe with a strong legislative basis to increase competition and stimulate growth in the broadband market. Erkki Liikanen, European Commissioner for the Information Society, observed, "The Commission believes that a technology-neutral approach, where the user chooses from an open marketplace, should be central to a new European broadband strategy. We need to develop this strategy as soon as possible" (eEurope, 2002, February 12). Thus, the most likely solution for Western Europe in overcoming the digital divide is through public/private partnerships.

It should be noted that merely getting people online does not solve the digital divide. Recent research has shown that being "connected" does not mean that a user can effectively access or manage online content (Hargittai, 2002, August). In addition, as Malcolm Forbes, managing director of Brixton Online, noted in a May 2002 interview, the digital divide "is simply a manifestation of the same old social divides that have their roots in poverty, low expectations and opportunities" (Digital Europe, 2002, May 16). Though access is not a sufficient condition to solving the digital divide, it is a necessary one. Inequality in access to communication technology is too important a social problem to ignore.

\section{References}

Bazar, B. \& Boalch, G. (1997). A preliminary model of Internet diffusion within developing countries [online]. Available: http://ausweb.scu.edu.au/proceedings/boalch/paper.html.

BBC News Online (2000, July 22). "G8 Plans Hi-Tech Help for Poor."

BBC News Online (2001, January 30). "Digital Divisions Split Britain."
BBC News Online (2002, August 21). "Gender Interests Divide Silver Surfers."

Burt, R. (1980). Innovation as a structural interest: Rethinking the impact of network position on innovation adoption. Social Network, 2, 327-355.

Burt, R. (1987). Social contagion and innovation: Cohesion versus structural equivalence. American Journal of Sociology 92, 1287-1335.

Clemente, P. (1997). The state of the NET: The new frontier. New York: McGraw-Hill.

Commission of the European Communities (2001). E-Inclusion: The Information Society's potential for social inclusion in Europe. Commission Staff Working Paper.

Digital Europe (2002, May 16). "Interview: 'I don't think that by getting people 'online' we will have solved the digital divide."”

eEurope (2002, February 12). eEurope: Taking stock of results and setting priorities for the Barcelona European Council. Brussels: European Commission.

eMarketer (1999, September 7). "The eEurope Report."

Granovetter, M. (1978). Threshold models of collective behavior. American Journal of Sociology, 83, 1420-1443.

Hampton, K., O'Bryant, R. \& Pinkett, R. (2002, August). Beyond the Digital Divide: Using Community Technology to Expand Social Networks, Build Social Capital and Inspire Empowerment in a Low-income Boston Neighborhood. Paper presented at the annual convention of the American Sociological Association, Chicago, IL.

Hargittai, E. (1999). Weaving the western web: Explaining differences in internet connectivity among OECD countries. Telecommunications Policy 23, 701-718.

Hargittal, E. (2002, August). Second-Level Digital Divide: Differences in people's ability to find information online. Paper presented at the annual convention of the American Sociological Association, Chicago, IL.

Hillebrand, M. (2000, January 31). "3Com Funds 'Digital Divide' Programs in 10 U.S. Cities," E-Commerce Times.

International Telecommunications Union [ITU] (2000). "Internet Indicators."

Kwon, H. (2001, August). The global internet diffusion. Paper presented to the annual convention of the Association for Education in Journalism and Mass Communication, Washington, DC.

Markus, M. L. (1987). Toward a "critical mass" theory of interactive media: Universal access, interdependence and diffusion. Communication Research, 14 (5), 461-511.

Markus, M. L. (1991). Toward a "critical mass" theory of interactive media. In J. Fulk \& C. Steinfield (Eds.). Organizations 
and communication technology (pp. 194-218). Newbury Park, CA: Sage.

Media Guardian (2002, March 11). "Regional Disparities Reveal Gulf in Internet Access." Available at: http://media.guardian.co.uk/newmedia/story/0,7496,665708,00. $\underline{\mathrm{html}}$

Meland, M. (2000, May 23). Forbes.com.

Morris, M. \& Ogan, C. (1996). The Internet as mass medium. Journal of Communication, 4 (1), 39-50.

National Public Radio/Kaiser Family Radio/Kennedy School of Government (2000, February). Survey of Americans on technology. Cambridge, MA: Kennedy School of Government.

NUA Internet Surveys (2000, June 1). "Digital Divide Persists in Europe."

NUA Internet Surveys (2000, November 24). "Europe: Fewer Users, Greater Divide Than US."

NUA Internet Surveys (2001, November 1). "How Many Online?"

NUA Internet Surveys (2002, September 1). "How Many Online?"

Oliver, P., Marwell, G., \& Teixeira, R. (1985). A theory of critical mass: I. Interdependence, group heterogeneity, and the production of collective action. American Journal of Sociology, 91 (3), 552-556.

Organization for Economic Co-operation and Development [OECD] (2001). "Understanding the Digital Divide."

Page, D. (2000, December). "Building the Digital Bridge in Boston," ConvergeMag.com.

PowerUP (2002, September 1). "Partnerships." Available at: http://www.powerup.org

Rogers, E. M. (1983). Diffusion of innovations (3rd ed.). New York: Free Press.

Rogers, E. M. (1986). Communication technology: The new media in society. New York: Free Press.

Rogers, E. M. (1991). The 'Critical Mass' in the diffusion of interactive technologies in organizations. The Information Systems Research Challenge: Survey Research Methods. Cambridge, Mass: Harvard Business School Press.

Rogers, E. M. (1995). Diffusion of innovations (4th ed.). New York: Free Press.

Rogers, E. M., with Shoemaker, F. (1971). Diffusion of innovations (2nd ed.). New York: Free Press.
Rosen, J. (2000, April 3). "Maine Proposes Laptops for Students," online journal civic.com.

Tapscott, D. (1997). Growing up digital. New York: McGraw Hill.

Thierer, A. (2000, April 20). How free computers are filling the digital divide, The Heritage Foundation.

Thierer, A. (2000, February 1). Digital Divide or a Digital Deluge of Opportunity? The Heritage Foundation.

U.S. Department of Commerce (2000, October). "Falling Through the Net: Toward Digital Inclusion," National Telecommunications and Information Administration.

Valente, T. (1993). Diffusion of innovations and policy decisionmaking. Journal of Communication, 43, 30-45.

Valente, T. (1995). Network models of the diffusion of innovation. Cresskill, New Jersey: Hampton Press, Inc.

Wakefield, J. (2002, March 14). "Europe lags in internet race," BBC Online. Available at: http://news.bbc.co.uk/hi/english/sci/tech/newsid 1866000/1866 $\underline{980 . s t m}$

\section{Biographies}

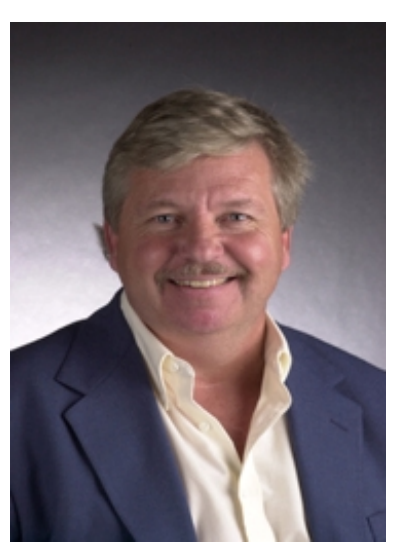

Rod Carveth is Associate Professor of Advertising at Texas Tech University in Lubbock, Texas, USA. He is author of Media Economics: Theory and Practice, as well as several articles and papers on the digital divide. He is also co-chair of the Task Force on the Digital Divide.

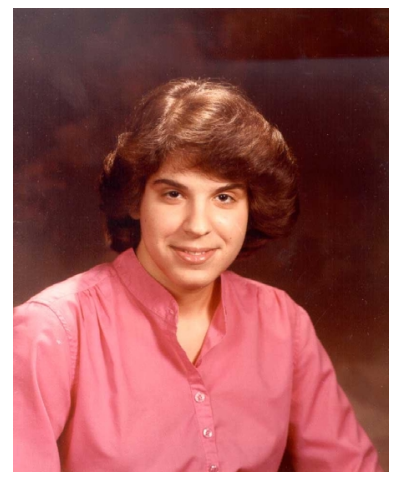

Susan B. Kretchmer (The Johns Hopkins University) is the author of numerous papers, articles, and book chapters on information and communication technology issues and the digital divide. Her work explores the historical, social, and cultural relationship between communication and technology in popular media, law and public policy, and social change. She is co-chair of the Task Force on the Digital Divide. 